Angelaki

Journal of the Theoretical Humanities

\title{
REMOTE VISION EXPERIMENTS: A PHOTO ROMAN
}

To cite this article: (2019) REMOTE VISION EXPERIMENTS: A PHOTO ROMAN, Angelaki, 24:1, i-xv, DOI: 10.1080/0969725X.2019.1606485

To link to this article: https://doi.org/10.1080/0969725X.2019.1606485

曲 Published online: 17 Apr 2019.

Submit your article to this journal $\pi$

Џ Article views: 1

View Crossmark data 
REMOTE VISION EXPERIMENTS A PHOTO ROMAN 


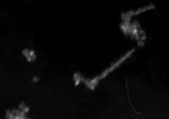

3.

$-4$

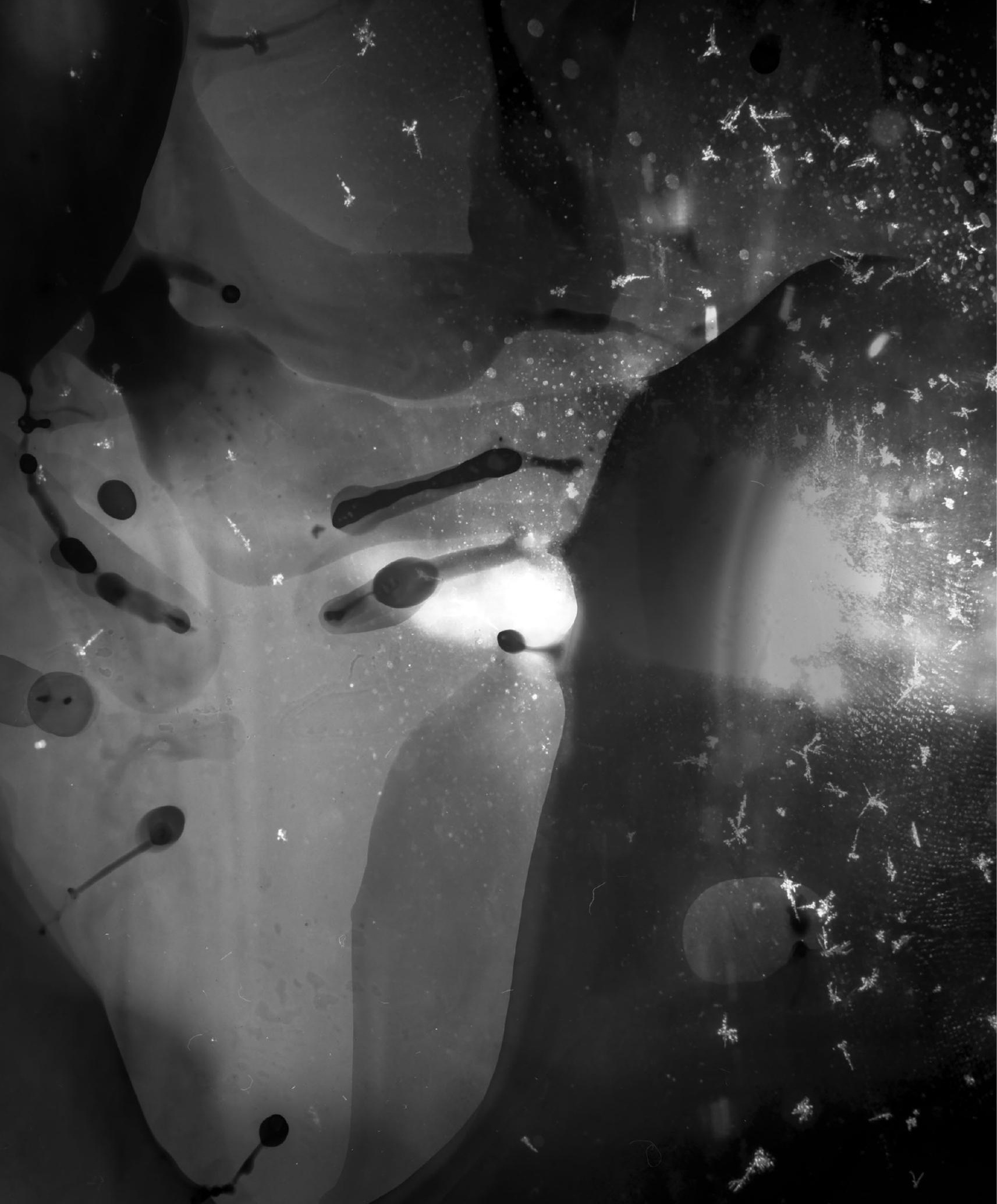




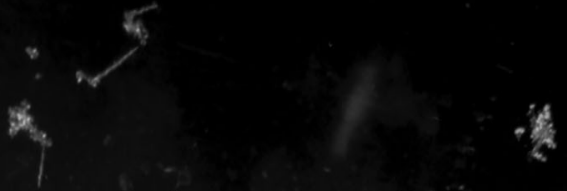

H

1

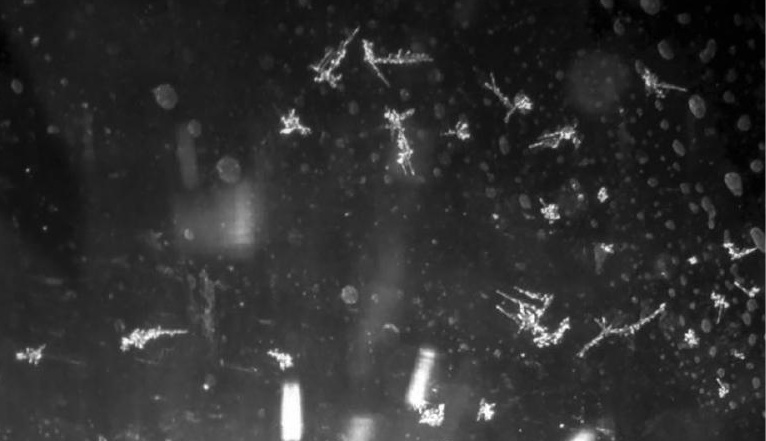

$0 \quad \therefore \quad \therefore \quad \because \because \because 4$ a

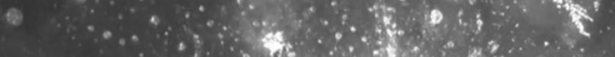

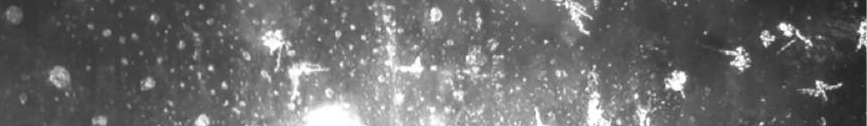

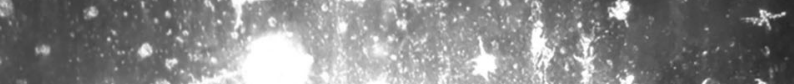

$t$

k

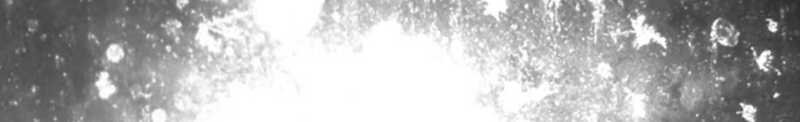

2. 2.2

$x$

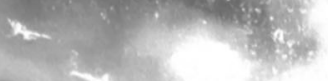

t
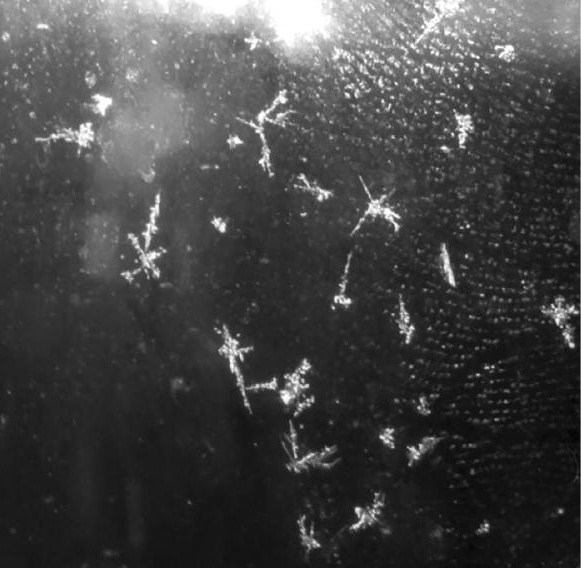

\&

\&

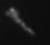

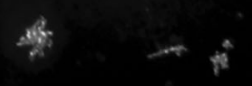

$x^{*}$

(C) LUKE PEWHDELEt 2019 

A) 1

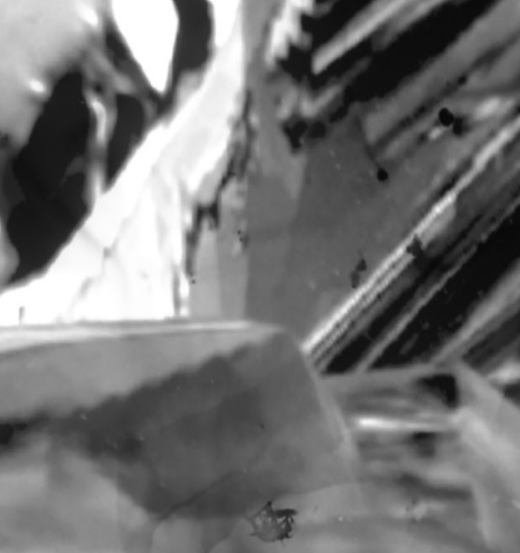

$0=$
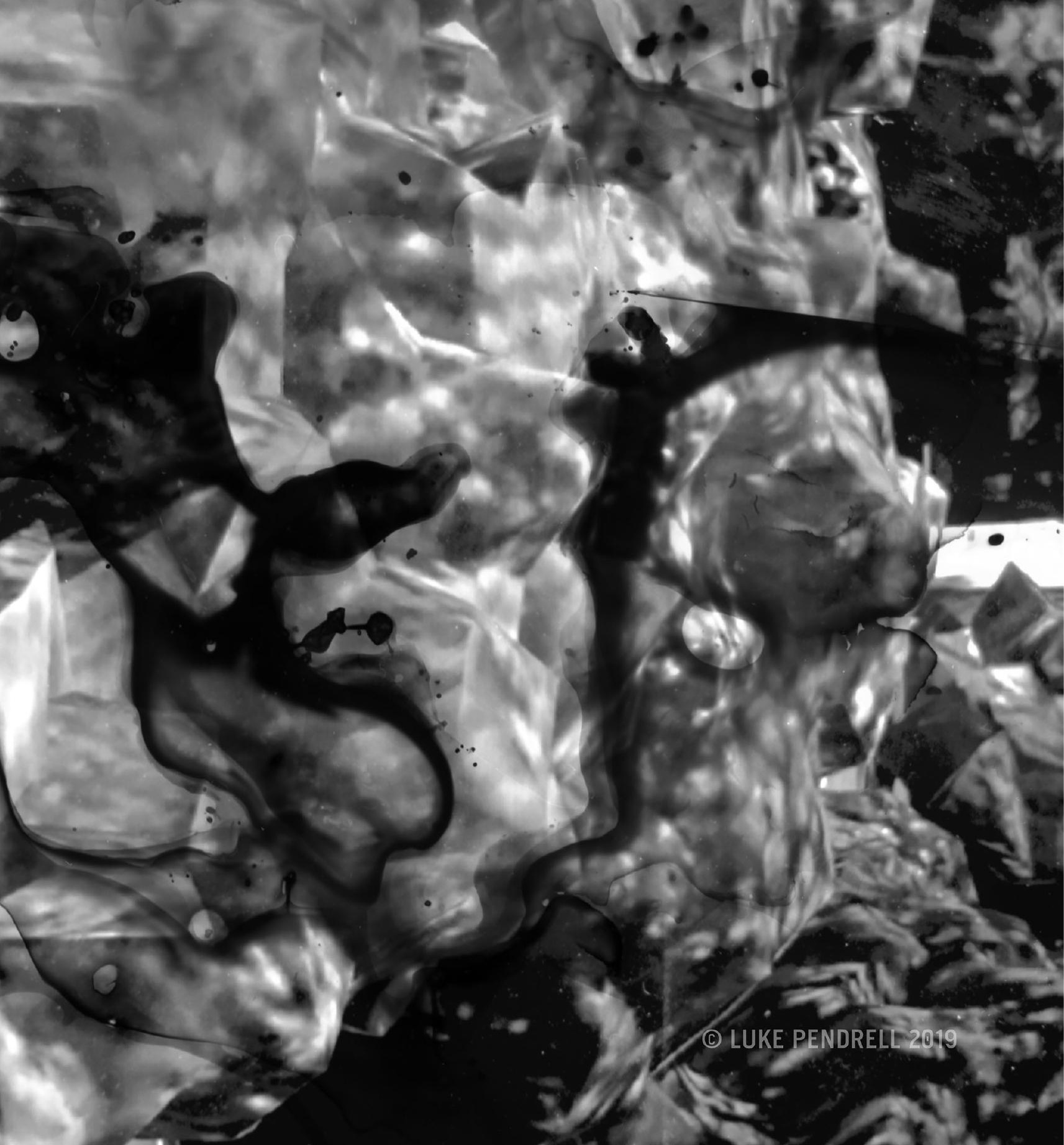

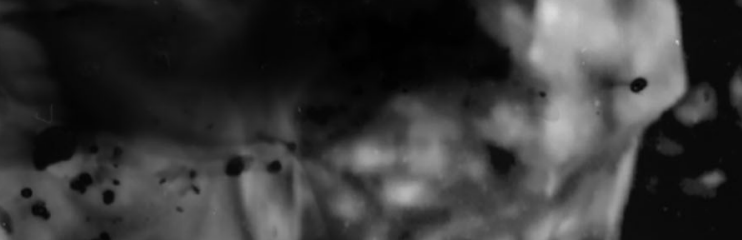



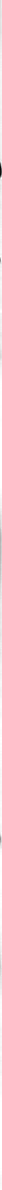

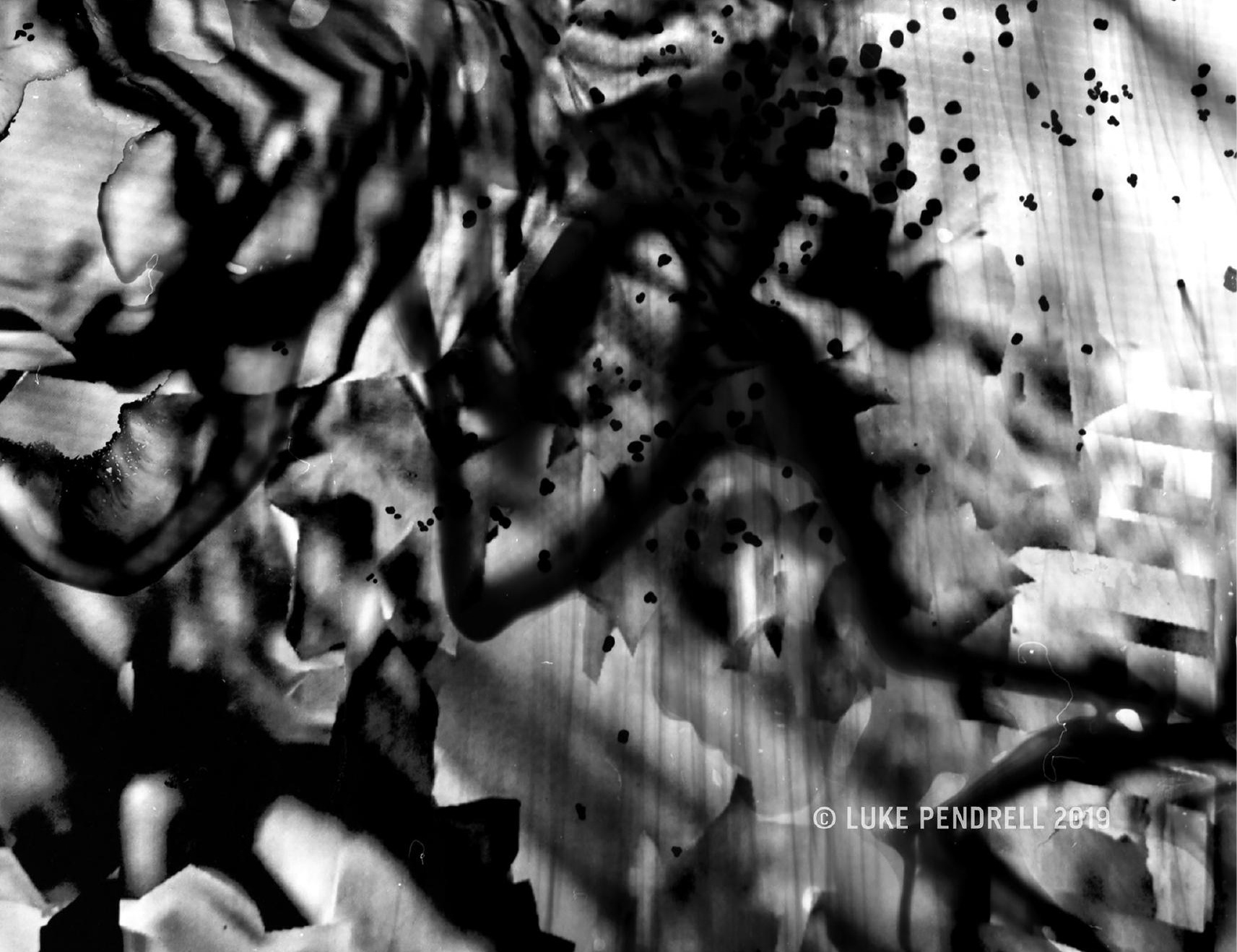




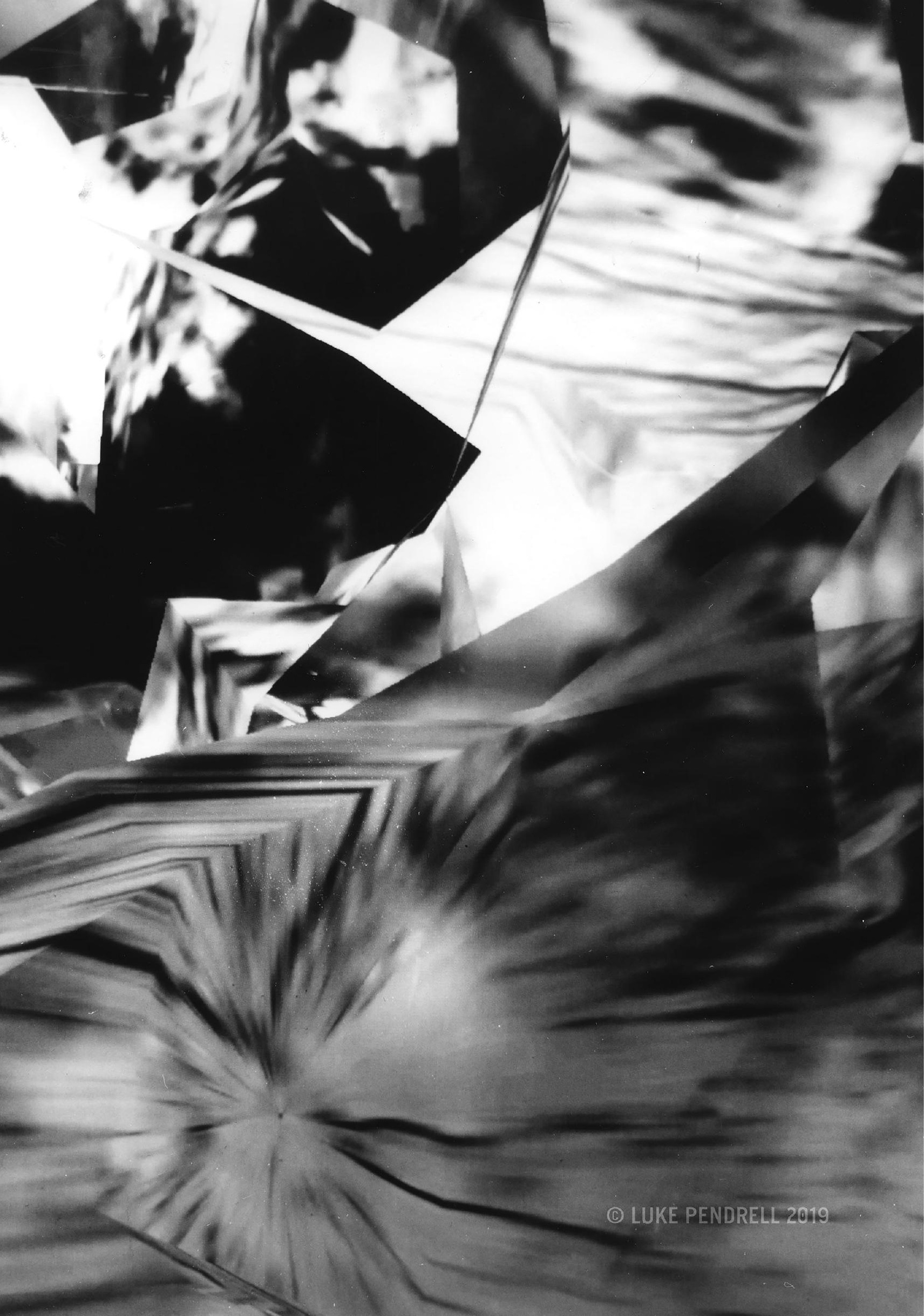




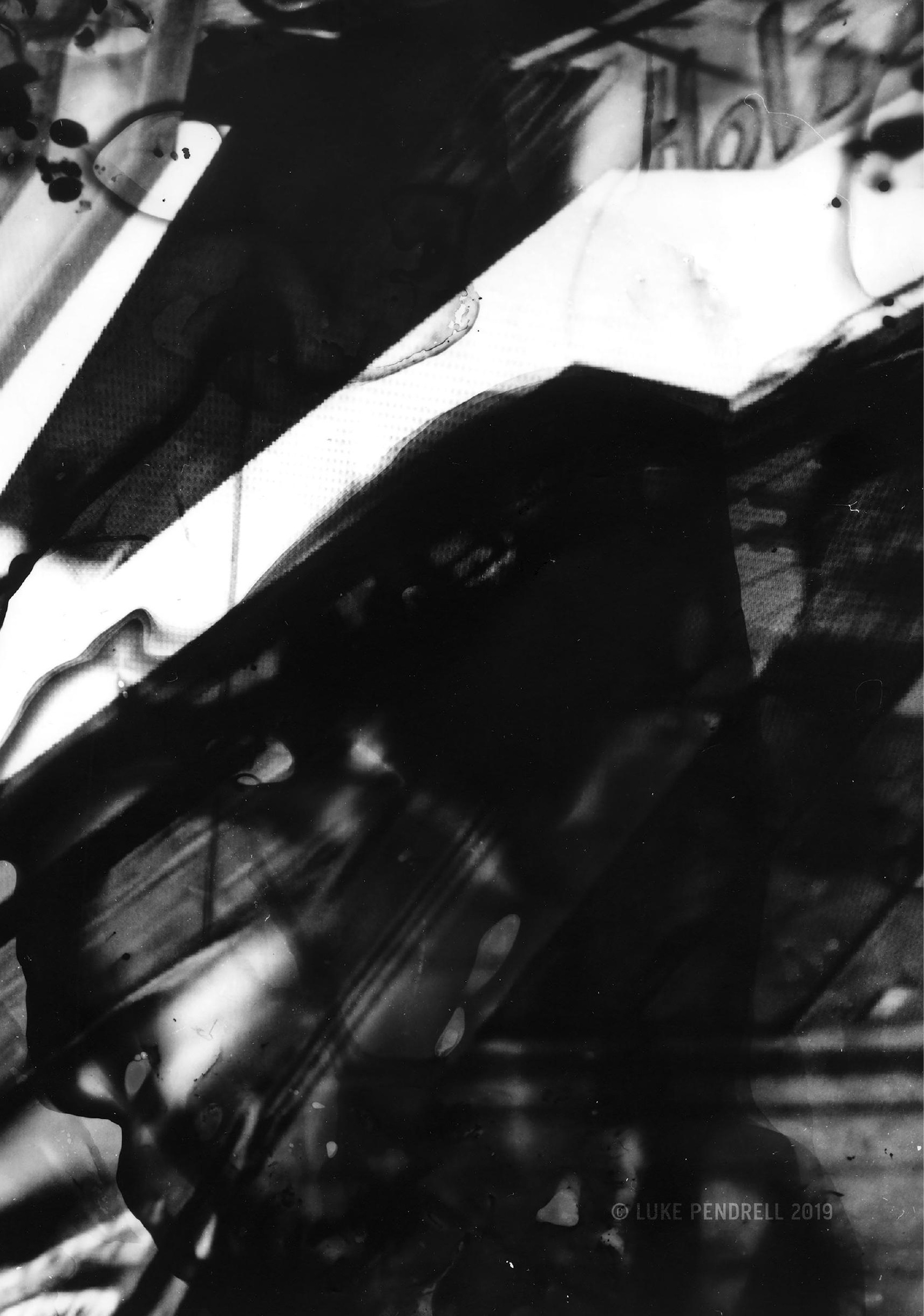




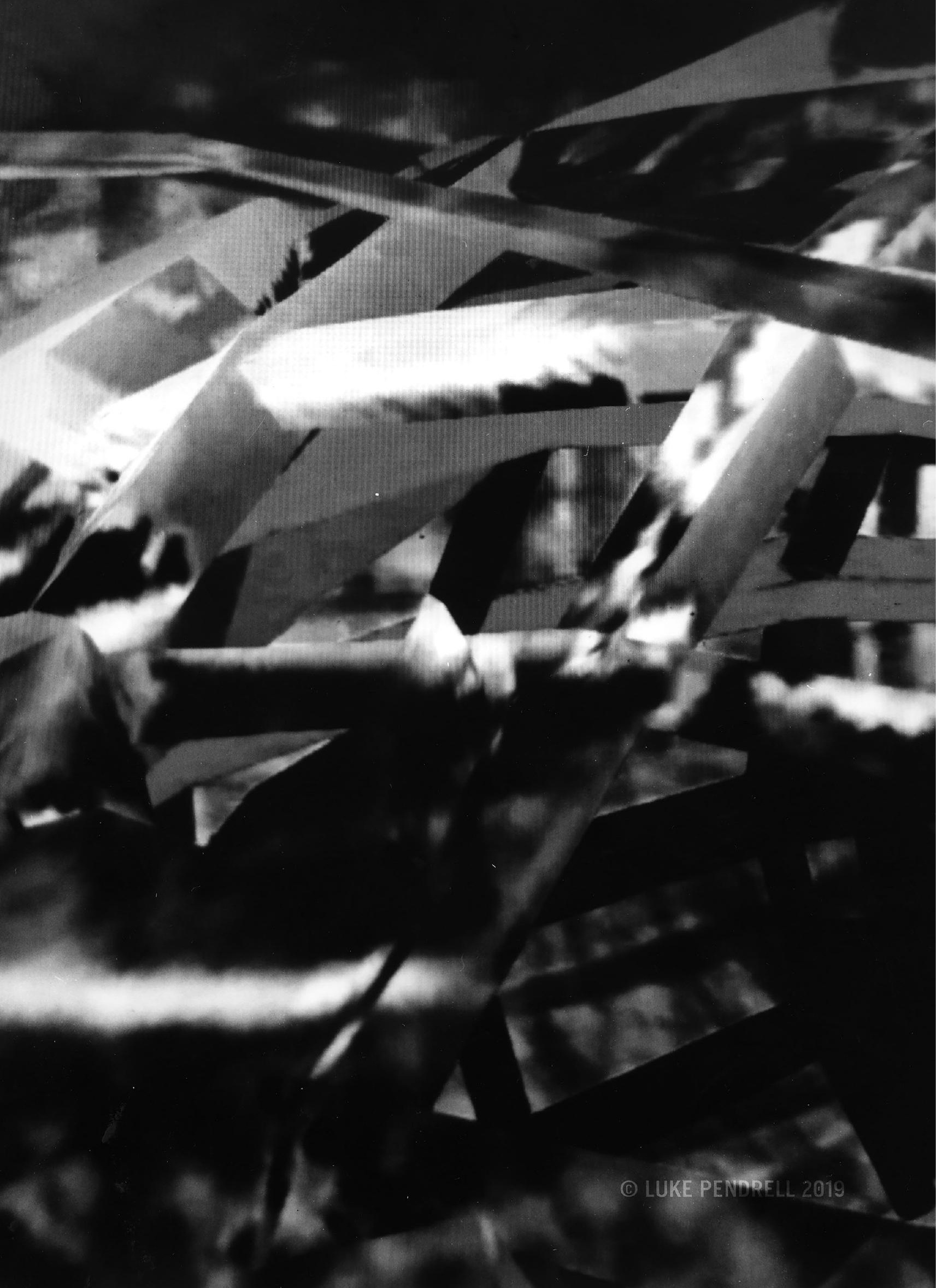




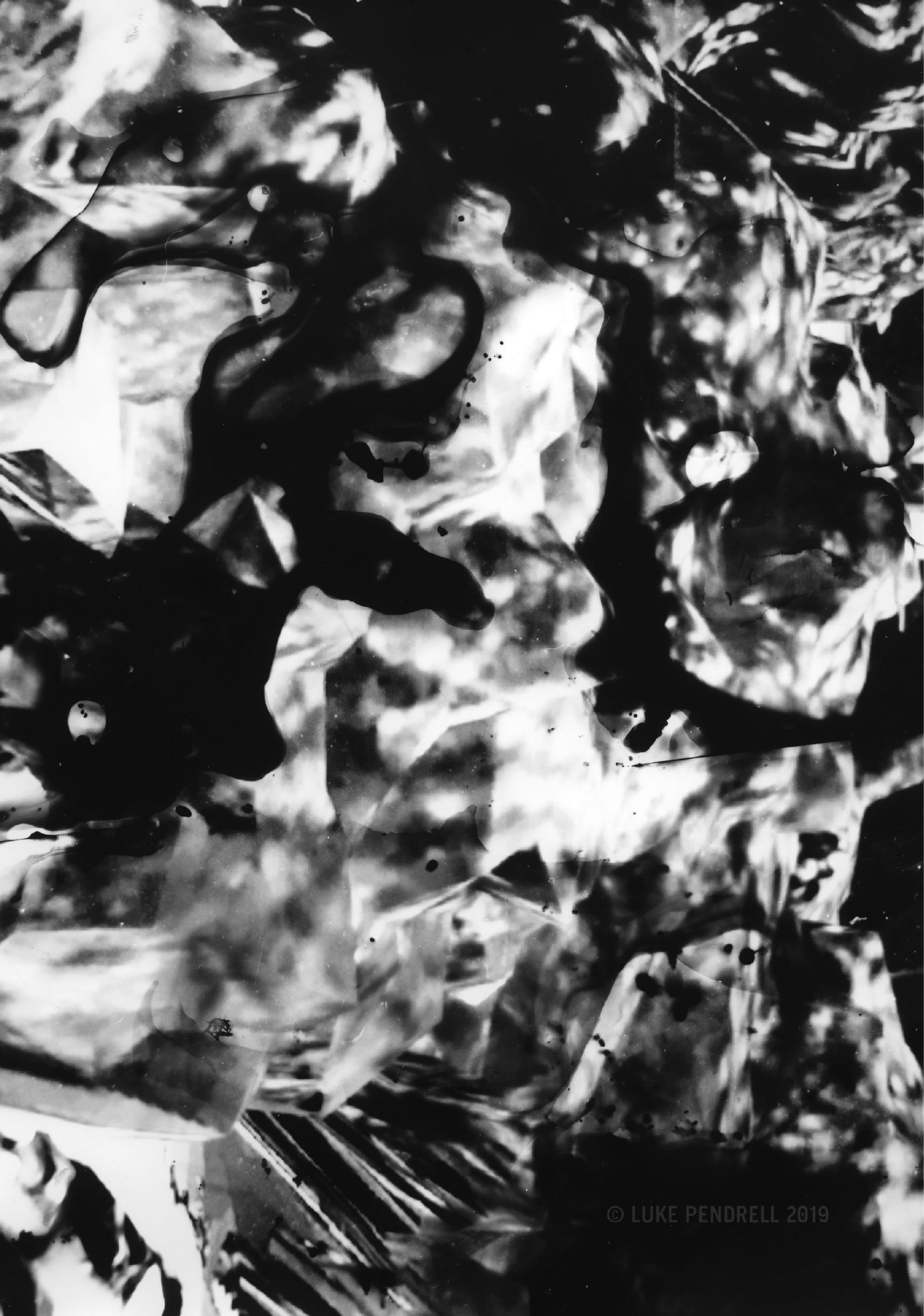




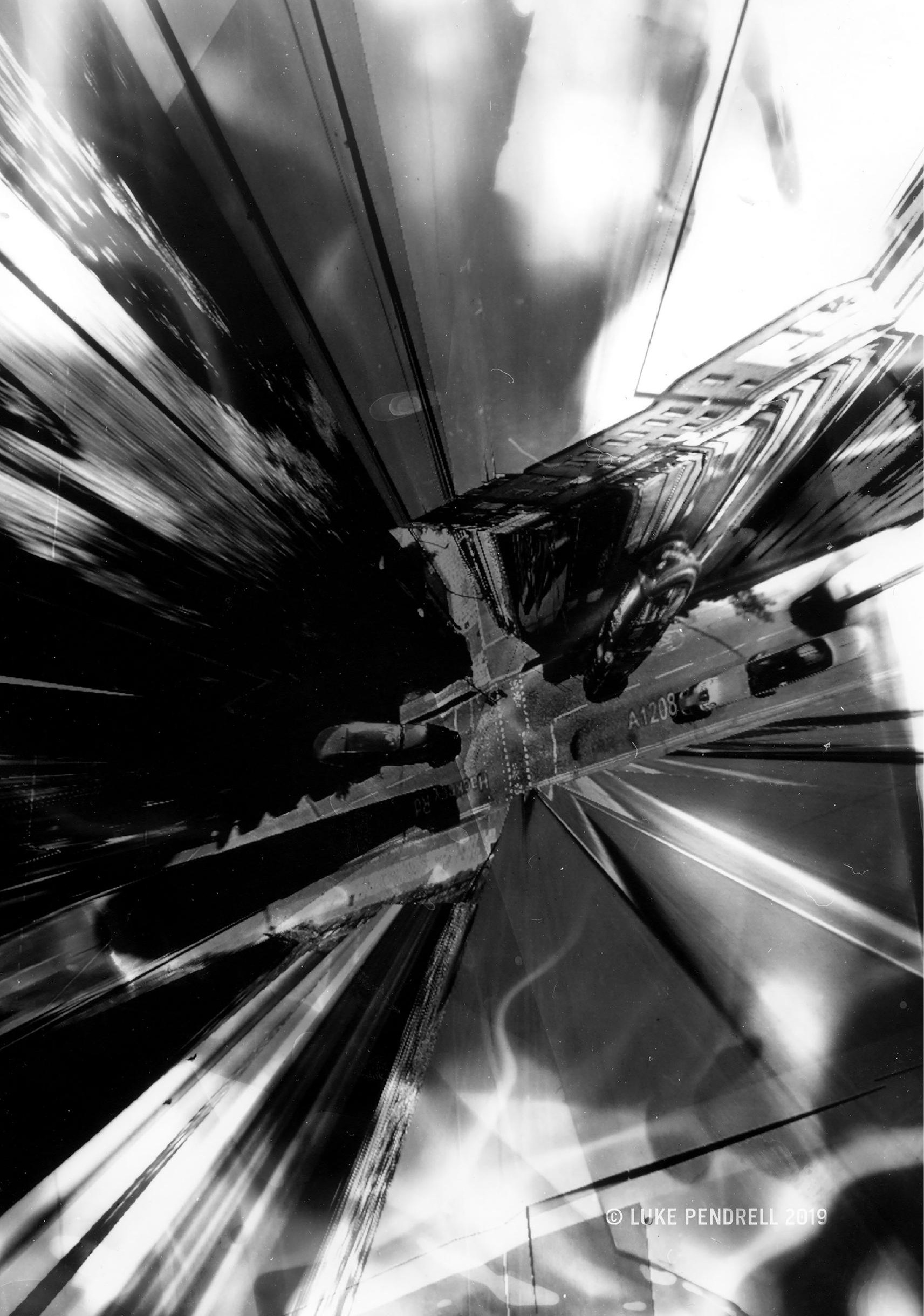


